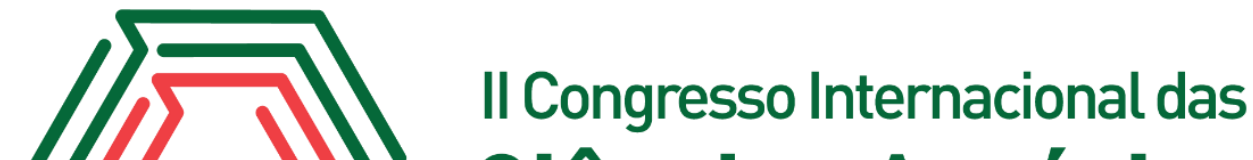 Ciências Agrárias COINTER - PDVAgro 2017
}

\section{POTENCIAL HÍDRICO, REDUTASE DE NITRATO, NITRATO, AMÔNIO, AMONIÁCIDOS E PROTEÍNAS EM PROGÊNIES DE CUPUAÇUZEIRO Theobroma grandiflorum SUBMETIDAS À DEFICIÊNCIA HÍDRICA.}

\begin{abstract}
Diana Jhulia Palheta de SOUSA ${ }^{1}$; Juscelino Gonçalves PALHETA ${ }^{2}$; Marcelo Murad MAGALHÃES ${ }^{3}$; Roberto Lisboa CUNHA ${ }^{4}$; Cândido Ferreira de Oliveira NETO ${ }^{5}$
\end{abstract}

\section{Introdução}

O cupuaçuzeiro [Theobroma grandiflorum (Willd. ex. Spreng.) Schum.,] é uma árvore pertencente a família Malvaceae, nativa da Amazônia. Com alto potencial para o desenvolvimento agrícola e agroflorestal da região Norte do Brasil, tal espécie é encontrada em estado rústico nas florestas tropicais de terra firme na parte sul e sudeste da Amazônia Oriental e Noroeste do Estado do Maranhão (ALVES et al., 2012).

Nos últimos anos o plantio do cupuaçuzeiro no Estado do Pará, vem sendo realizado em regiões com os menores volumes de chuva, visando à prevenção da Vassoura de bruxa (Moniliophtera perniciosa), contudo não há respostas sobre o comportamento dessa espécie em condição de restrição hídrica. Desse modo, o trabalho teve o objetivo de avaliar o potencial hídrico, redutase de nitrato, nitrato, amônio, amoniácidos e proteínas em progênies de cupuaçuzeiro Theobroma grandiflorum submetidas à tolerância hídrica. Tendo como hipótese que à deficiência hídrica irá alterar as variáveis estudadas.

\section{Fundamentação Teórica}

A deficiência hídrica afeta no mecanismo de absorção e assimilação de água e nutrientes pelas plantas (LECHINOSKI et al., 2007).A capacidade das plantas para suportar a deficiência hídrica é caracterizada por vias fisiológicas e bioquímicas, que promovem a retenção ou aquisição de água (BOHNERT, 1996).

\footnotetext{
${ }^{1}$ Agronomia, Universidade Federal Rural da Amazônia, dianajhuliap@gmail.com

2 Pós-graduação em Ciências Florestais, Universidade Federal Rural da Amazônia, juscegoncalves@hotmail.com

${ }^{3}$ Doutorado em Ciências dos Alimentos, Universidade Federal de Lavras, marcelo.magalhaes@empraba.br

${ }^{4}$ Doutorado em Ciências Agrárias, Universidade Federal de Viçosa, roberto.cunha@embrapa.br

${ }^{5}$ Professor doutor, Universidade Federal Rural da Amazônia, candido.neto@ufra.edu.br
} 


\section{Metodologia}

O experimento foi conduzido na casa de vegetação da Embrapa Amazônia Oriental, localizada no município de Belém-PA, no período de Março a Novembro de 2016 (26/04/2016 à 16/11/2016). Utilizou-se as progênies 32, 42, 46, 47, 57, 215 e 1074 de cupuaçuzeiro com 8 meses de idade, oriundas de sementes de clones parentais do cultivar BRS Carimbó do Programa de Melhoramento Genético da Embrapa Amazônia Oriental. O delineamento experimental foi inteiramente casualizado (DIC) em esquema fatorial $2 \times 7$ com 5 repetições. A irrigação foi suspensa por 16 dias nas plantas submetidas à deficiência hídrica. Foram analisados o potencial hídrico (DaMatta et al. 1993), a concentração de nitrato (Cataldo et al., 1975), a determinação da atividade da redutase do nitrato (Hageman; Hucklesby, 1971), a concentração de amônio (Weatherburn, 1967), a concentração dos aminoácidos (Peoples et al., 1989), e a concentração das proteínas (Bradford, 1976). Os resultados foram submetidos aos testes de Shapiro - Wilks (SHAPIRO \& WILKS, 1965), e levene (BOX, 1953) .

\section{Resultados e Discussões}

Em relação ao potencial hídrico antemanhã, as progênies 32, 42, 46, 47, 57, 215, 1074 submetidas à deficiência hídrica obtiveram um decréscimo significativo de 1.462\%, 622\%, 1.288\%, $1.100 \%, 1.066 \%, 1.288 \%$ e $2.438 \%$ respectivamente (Figura 1A). Enquanto ao potencial hídrico do xilema apresentaram uma diminuição de 68\%, 65\%, 123\%, 117\%, 83\%, 68\% e 642\%, respectivamente (Figura 1B). Isso pode ter ocorrido em função da baixa disponibilidade de água no solo ocasionando a decomposição das raízes (TAIZ \& ZAIGER, 2013).

Figura 1: Potencial hídrico antemanhã (A) e xilemático(B) em folhas de progênies de Theobroma grandiflorum, submetidas à deficiência hídrica e a irrigação. Fonte: Própria
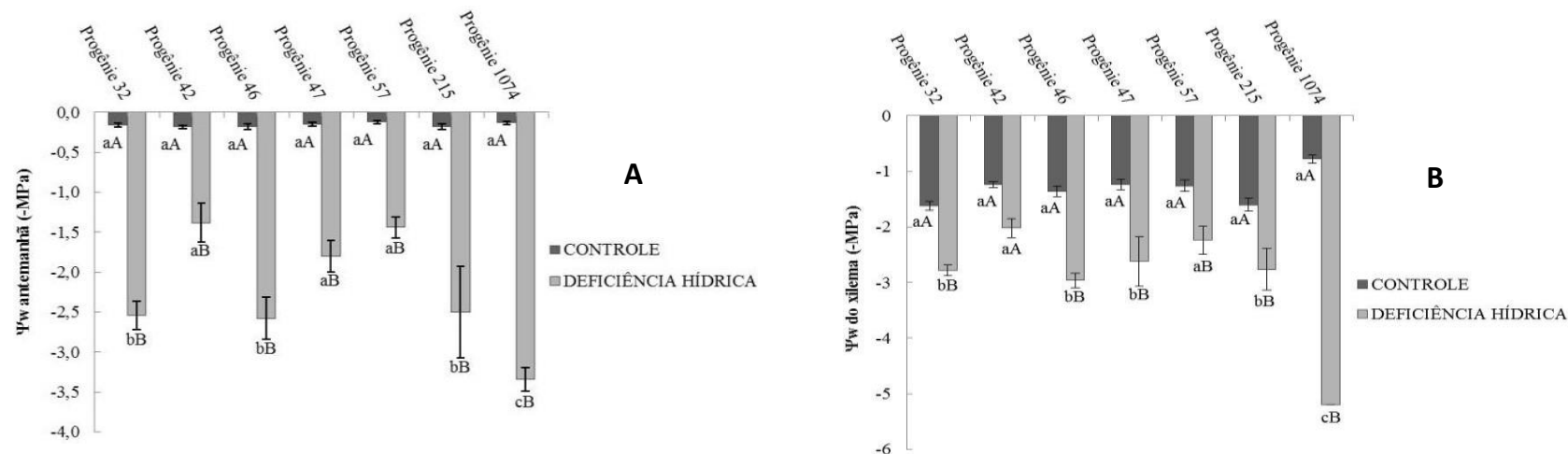

Em relação às concentrações de nitrato, houve redução no tecido foliar para as progênies 32,

47, 57, 215 e 1074 submetidas à deficiência hídrica, de 70\%, 72\%, 27\% 60\% e 47\%, respectivamente (Figura 2A). Para a raiz às progênies 32, 46, 47, 57, 215 e 1074 corresponderam a 
uma redução significativa de 63\%, 42\%, 63\%, 72\%, 28\% e 59\%, respectivamente (Figura 2B). Quanto às atividades da redutase do nitrato no tecido foliar as progênies 32, 42, 46, 47, 57, 215 , 1074 apresentaram um decréscimo de 80\%, 40\%, 87\%, 77\%, 77\%, 91\% e 99\%, respectivamente (Figura 3A). Também foi observada redução significativa no tecido radicular na atividade da redutase de nitrato para as progênies 32, 42, 46, 47 e 215 de 42\%, 37\%, 41\%, 79\% e 25\%, respectivamente (Figura $3 \mathrm{~A})$.

A diminuição da concentração de nitrato nas folhas e raízes de Theobroma grandiflorum, pode está associada á redução de água no solo e consequentemente a restrição da assimilação de nitrato do solo pelas raízes, refletindo com isso na baixa atividade da enzima redutase do nitrato (RN) nas folhas e raízes, tendo em vista que a enzima depende do fornecimento de nitrato (SHANER; BOYER, 1976).

Figura 2: Concentração de nitrato ( $\mathrm{A}$ - folhas; $\mathrm{B}$ - raízes) e atividade da redutase de nitrato $(\mathrm{C}$ - folhas; $\mathrm{D}$ raízes) de progênies de Theobroma grandiflorum, submetidas à deficiência hídrica e a irrigação. Fonte: Própria
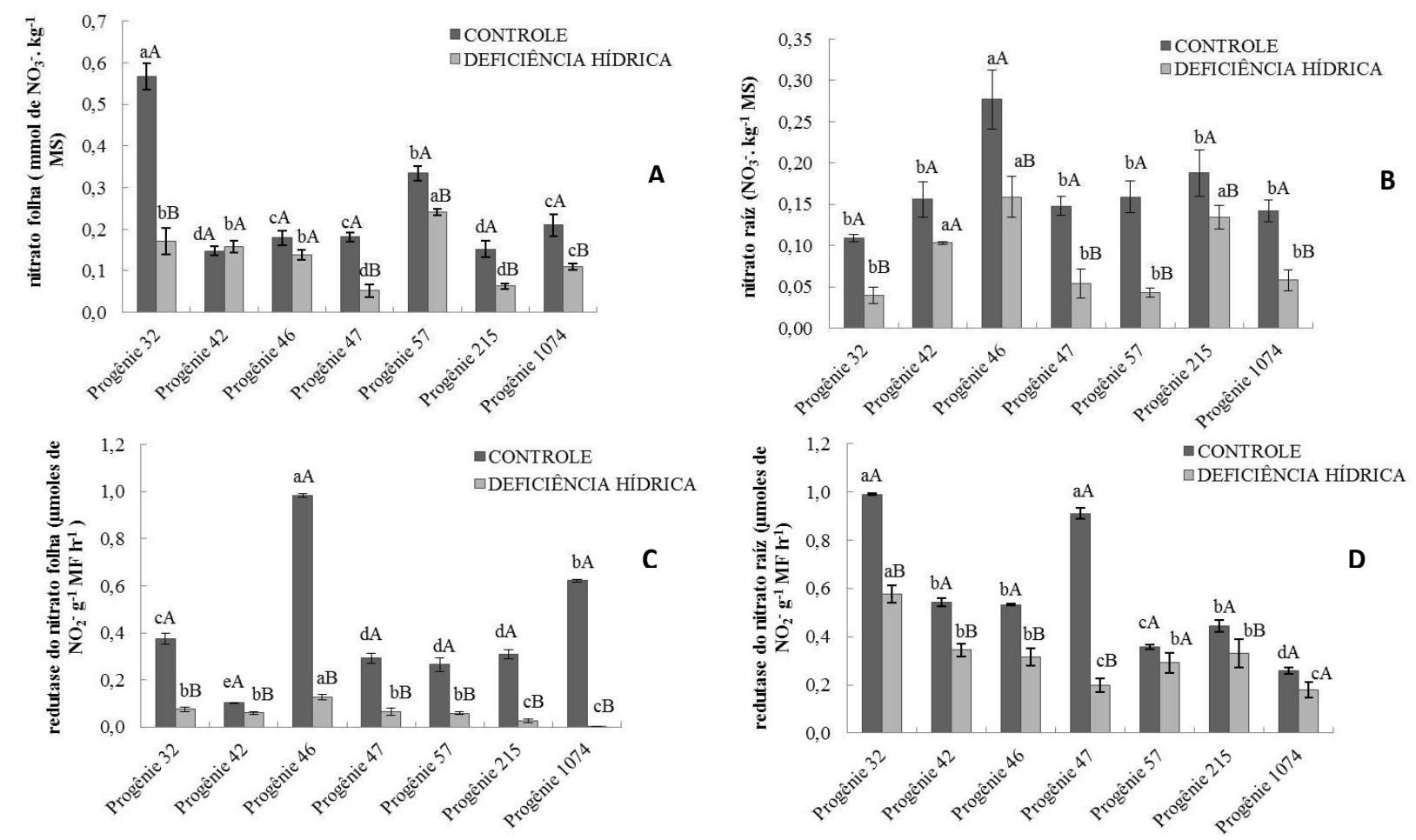

Quanto ao teor de NH4+, a deficiência hídrica promoveu o aumento nos tecidos foliares das progênies 46, 47, 215 e 1074 de 38\%, 25\%, 30\% e 83\% respectivamente, comparado às progênies submetidas aos tratamentos controle (Figura 4A). Para a raiz (Figura 4B), também foi observado um aumento significativo, nas progênies 32, 42, 47, 57 e 215 de 17\%, 16\%, 44\%, 16\% e 28\% respectivamente. As plantas quando estão sujeita a deficiência hídrica, podem induzir a formação de 
amônio por meio da proteólise, ou através da indução de outras rotas de formação desse composto (TAIZ \& ZEIGER, 2013).

Figura 3: Concentração de amônio livre (A - folhas; B - raízes) progênies de Theobroma grandiflorum, submetidas à deficiência hídrica e a irrigação. Fonte: Própria

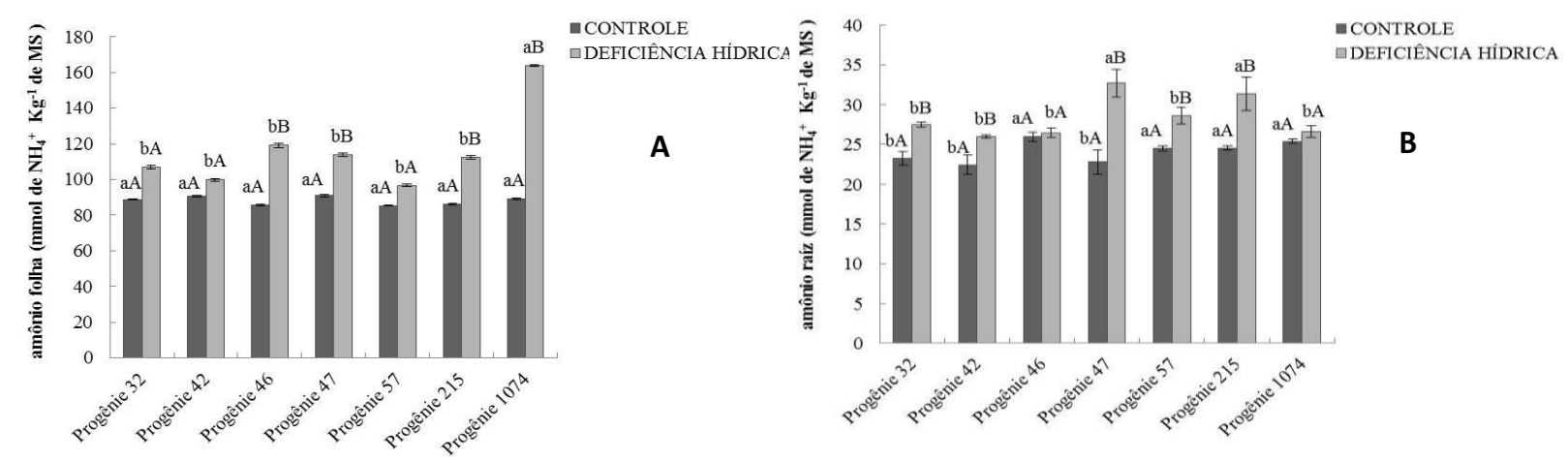

Em relação à concentração de aminoácidos os resultados obtidos no tecido foliar das progênies 32, 42, 46, 47, 57, 215 e 1074 representaram um aumento significativo de 20\%, 44\%, 42\%, 46\%, respectivamente (Figura 4A). Em tecido radicular, as progênies 32, 42, 46, 47, 57 e 215 apresentaram um aumento significativo de 33\%, 31\%\%, 16\%, 43\% 12\% e 29\%, respectivamente (Figura 4B). Esse comportamento pode ser atribuído à alteração do metabolismo do nitrogênio, com redução da síntese de proteína e acúmulo de aminoácidos (BRITO et al. 2008).

Figura 4: Concentração de aminoácidos solúveis totais (A - folhas; B - raízes) de progênies de Theobroma grandiflorum, submetidas à deficiência hídrica e a irrigação. Fonte: Própria

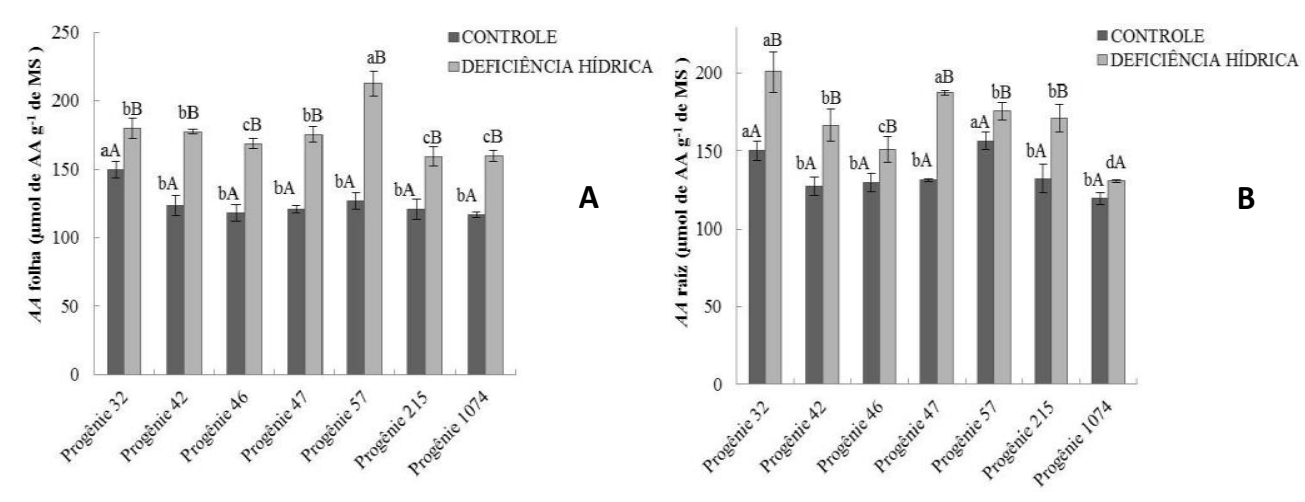

A concentração de proteínas solúveis totais (PST) em tecido foliar nas progênies 32, 42, 46 e 57 submetidas à deficiência hídrica indicaram um aumento de 348\%, 80\%, 156\% e 535\%, respectivamente (Figura 5A). No tecido radicular (Figura 5B), a progênie 215 apresentou um aumento de $51 \%$ comparada a controle. O acréscimo do teor de proteínas em progênies possivelmente está associada ao aumento da concentração de aminoácidos apresentado pelas 
plantas.

Figura 5: Concentração de proteínas solúveis totais (A - folhas; B - raízes) de progênies de Theobroma grandiflorum, submetidas à deficiência hídrica e a irrigação. Fonte: Própria
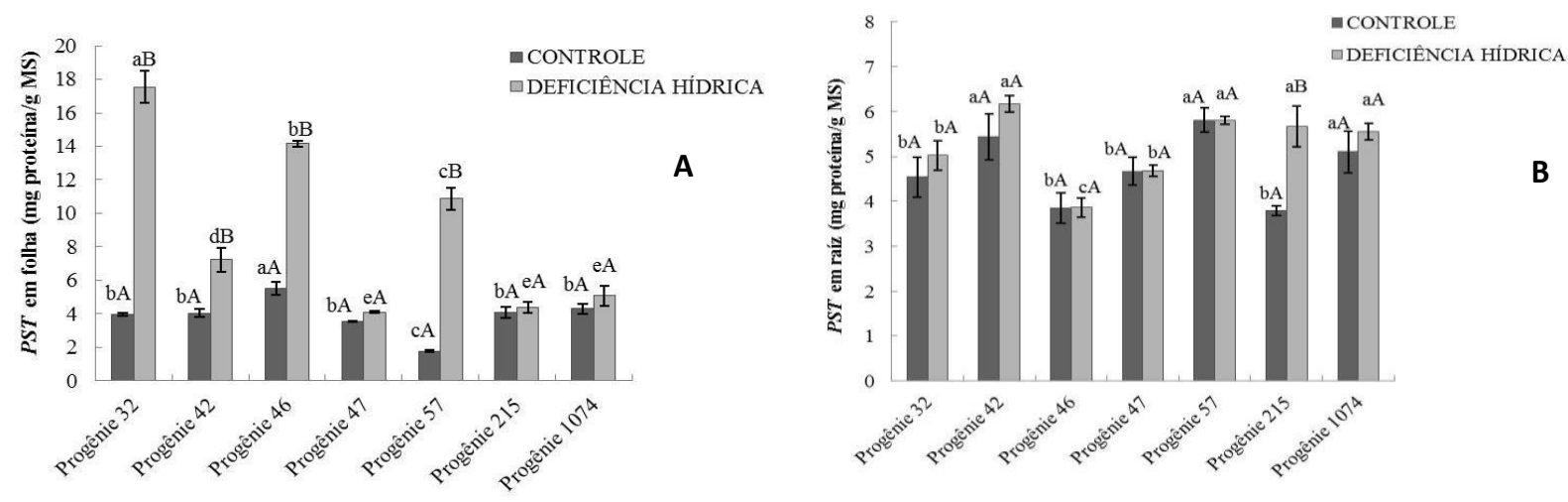

\section{Conclusões}

A deficiência hídrica alterou o metabolismo bioquímico das progênies de Theobroma grandiflorum, promovendo redução nas concentrações de nitrato, atividade da redutase do nitrato. No entanto, a deficiência hídrica também promoveu aumento nas concentrações de amônio, aminoácidos, proteínas.

\section{Referências}

ALVES, G. A. R.; SANTOS FILHO, B. G.; LOBATO, A. K. S.; YUEN TAN, D. K.; OLIVEIRA NETO, C. F.; COSTA, R. C.L.; ÁVILA, F.W.; MARQUES, D.J.; GALATE, R.S. Water relations, nitrogen compounds and enzyme activities in leaf and root of Young Yellow Lapacho (Tabebuia serratifolia) plants subjected to flooding. Plant Omics, v. 5, n. 3, p. 216- 222, 2012.

BOHNERT, H. J.; JENSEN, R. G. Strategies for engineering water stress tolerance in plants. Trends in Biotechnology. v. 14, p. 89-97, 1996.

BRITO, L.K.F.L.; SILVEIRA, J.A.G.; LIMA, L. L.F.; TIMÓTEO, A. R. S.;CHAGAS, R. M.; MARCEDO, C. E. C. alterações no perfil de frações nitrogenadas em calosde cana-deaçúcar induzidas por deficit hídrico. Pesquisa Agropecuária Brasileira, Brasília, v.43,n.6, p.683-690, 2008.

LECHINOSKI, A. L.; FREITAS, J. M. N.; CASTRO, D. S.; LOBATO, A. K. da S.; OLIVEIRA NETO, C. F.; CUNHA, R. L. M.; COSTA, R. C. L. Influência do estresse hídrico nos teores de proteínas e aminoácidos solúveis totais em folhas de Teca (Tectona grandis L. f.). Revista Brasileira de Biociências, v.5, p.927-929, 2007.

SHANER, D.L.; BOYER, J.S. Nitrate reductase activity in maize (Zea mays L.) leaves.

I. Regulation by nitrate flux. Plant Physiology, Maryland, v.58, p.499-504, 1976. 
TAIZ, L.; ZEIGER, E. Fisiologia Vegetal. 5ª ed. Porto Alegre: Artmed, p.918, 2013. 